\title{
Fostering Students' Creativity Through Innovative Learning Tools
}

\author{
Djamel Ghernaout ${ }^{1,2,{ }^{*} \text {, Mabrouk Touahmia }}{ }^{3}$, Mohamed Aichouni ${ }^{4}$, Abdulaziz Alghamdi ${ }^{5}$, \\ Noureddine Ait Messaoudene ${ }^{5}$
}

${ }^{1}$ Chemical Engineering Department, College of Engineering, University of Ha'il, Ha'il, Saudi Arabia

${ }^{2}$ Chemical Engineering Department, Faculty of Engineering, University of Blida, Blida, Algeria

${ }^{3}$ Civil Engineering Department, College of Engineering, University of Ha'il, Ha'il, Saudi Arabia

${ }^{4}$ Industrial Engineering Department, College of Engineering, University of Ha'il, Ha'il, Saudi Arabia

${ }^{5}$ Mechanical Engineering Department, College of Engineering, University of Ha'il, Ha'il, Saudi Arabia

Email address:

djamel_andalus@hotmail.com (D. Ghernaout)

${ }^{*}$ Corresponding author

\section{To cite this article:}

Djamel Ghernaout, Mabrouk Touahmia, Mohamed Aichouni, Abdulaziz Alghamdi, Noureddine Ait Messaoudene. Fostering Students' Creativity Through Innovative Learning Tools. Higher Education Research. Vol. 3, No. 1, 2018, pp. 9-14. doi: 10.11648/j.her.20180301.13

Received: February 3, 2018; Accepted: February 16, 2018; Published: March 15, 2018

\begin{abstract}
For the last two decades, creativity continued to occupy a prominent position in public as well as academic discourses in many parts of the world. As creativity depends on knowledge, curiosity, imagination, and evaluation, so focusing on these four pillars in education will increase its development. Fostering students' creativity and innovation capabilities has always been at the heart of universities' endeavor and engagement. The aim of this study is to illustrate the links between innovating learning tools and students' creativity. Media-reinforced cooperative studying domains may assist foster creative and critical thinking in net-generation business students; there are obstacles to the acceptation of these instruments both from the viewpoint of teachers and students. Regardless of these rejections, most students liked the non-linear, multi-media feature of the innovative learning domain and wanted more such actions to be advanced hereafter.
\end{abstract}

Keywords: Creativity, Innovation, Learning Tools, University, Student

\section{Introduction}

For the last two decades, creativity continued to occupy a major position in public as well as academic discourses. Recognized as a constituting element of knowledge societies, creativity is now considered as a major topic in all fields of the educational system. The term creativity has been considered as a central theme in all fields of education in many parts of the world. Skills related to creativity such as problem solving, critical thinking, communication skill and collaboration have occupied an important place in many countries educational systems. Fostering students' creativity and innovation capabilities has always been at the heart of universities' endeavor and engagement. However, the main question addressed here is how to impregnate creativity in students and workers, for example, by innovating learning tools.
It is now recognized that the firms that reached the best level over the time are those who are the most focusing on creativity and innovation. These enterprises do not duplicate what others perform; as an alternative, they may employ advanced and original schemes from others as a jumping-off point to rise up with a distinctive implementation, output, or support for themselves. They have a tendency to keep away themselves from the rivalry rather than compete with them. If they discern another enterprise duplicating what they perform, they bring into being something fresh and of higher quality. In a different manner, they are qualified to use their creativity and their innovative powers to maximum advantage in order to achieve long-range prosperity [1].

Although more spending on education does not always lead to greater innovation, low spending on research and development can certainly obstruct both innovation and economic performance [2]. Sternberg [3] argued that society can play a role in the development of creativity by increasing 
the rewards and decreasing the costs. Al-Sudairi and Bakry [4] emphasized the need for building a knowledge national culture that promotes people's drive towards knowledge generation and innovation and towards making efficient utilization of the newer technology. Mayfield and Mayfield [5] developed a scale to measure workers creative environment perceptions. They concluded that workers' creative output can be significantly increased by improving organizations' creative environment. Iqbal [6] presented an overview of the state of creativity and innovation in Saudi Arabia and discussed the low level of creative outcomes reported in the Global Innovative Index. Thus, to succeed in the global innovation game, universities are increasingly expected to provide more opportunities that foster student's cognitive and creative potential. More importantly, they should maintain a relatively high level of research and development spending and demonstrate creativeness and innovativeness in their curricula. Touahmia et al. [7] argued that a strong link exists between curriculum and creativity and innovation development. Therefore, a great deal of importance should be granted to including material that can contribute to fostering creativity and innovation among students in academic curricula.

This study aims to illustrate the links between innovating learning tools and creativity at universities. The project is funded by the Saudi Ministry of Education and aims to provide a better understanding of how creativity and innovation are applied in higher educational practice. The emphasis is on the effectiveness of Saudi universities support policy instruments to promote students' creativity during their learning process.

\section{Link Between Creativity and Innovation}

Creativity depends on knowledge, curiosity, imagination, and evaluation. The maximal your understanding foundation and degree of inquisitiveness, the more thoughts, patterns, and combinations you can achieve, which next corresponds to generating fresh and advanced and original products and services. However, simply possessing the understanding does not assure the generation of fresh models. The bits and pieces must be shaken up and returned in fresh fashions. Next, the primitive thoughts must be assessed and evolved into able to be used thoughts. In a different manner, there is an actual procedure [1].

As mentioned above, creativity and innovation are distinct. Creativity alludes to forming fresh and original thoughts. Innovation alludes to the implementation of a thought and, in several situations, is a cooperative project. Innovation is the spark that transforms healthy companies better. It's not only origination but as well a way of collective conduct convenient with fresh thoughts and risk. Firms that discern how to innovate do not automatically put funds into research and development. Alternatively they refine a fresh fashion of collective conduct that is convenient with fresh thoughts, revision, risk and even lack of success [1].

Creativity is the action of generating fresh thoughts, methods or activities, during the time that innovation is a fresh fashion of considering at and varying them. Creativity is at all times the beginning stage for innovation. Persons who possess a talent for creative innovations are inclined to vary from others in three manners [1]:

1. Expertise - specialized technological understanding in a specific field.

2. Creative thinking skills - suppleness and imagination as they concern issue resolution.

3. Intrinsic motivation.

The potential to think outside the box is better boosted in a supple, free, encouraging medium with a chief who considers his first function as helping rather than governing. Creative persons need this type of medium to originate, visualize, issue puzzle out, and generate new thoughts and notions. Creative thoughts appear when predetermined suppositions are disposed of and trials at fresh fashions that appear strange or unimaginable to others are examined [1].

\section{Creativity for Students}

\subsection{Most of Self-Made Millionaires Were not 'A' Students. Instead, They Are Self-Learning}

Following most teachers and most parents, it is easy to assume that getting good grades in school is a requirement for professional success [8,9].

As cited by Haden [9], Tom Corley, an accountant and financial planner, who surveyed a number of high net-worth individuals: Many of them are self-made millionaires [9] - It should be noted here that there is no need to be a millionaire to succeed [10]. Corley found most of the people surveyed did not earn high GPAs in school. Moreover, only $21 \%$ of the self-made millionaires were A students [11]. 41\% affirmed they were B students, and $29 \%$ were even C students. In other words, more of the self-made millionaires were $\mathrm{C}$ students than were A students $[9,12]$.

On the other hand, concerning the family history contribution, $59 \%$ of the self-made millionaires originated from middle-class households and $41 \%$ originated from poor households; demonstrating where you begin does not determine where you terminate [9].

As Corley [13] wrote....success in life does not come easy. It is fraught with pitfalls, obstacles, failure, and mistakes. Success requires persistence, mental toughness and emotional toughness in overcoming these pitfalls. Its pursuit pushes you to the edge emotionally and physically. You must grow a thick skin and become accustomed to struggle if you hope to succeed. Individuals who struggle academically may be more accustomed to dealing with struggle and making it a daily habit to overcome pitfalls.

Briefly, they begin to be cognitively strong [14], which generates a basis for long-term triumph [15]. As an illustration, effective persons are magnificent at making late satisfaction. Effective persons are magnificent at resisting 
lure. Effective persons are magnificent at beating apprehension with a view to realize what they want to realize. Naturally, that does not indicate they are not scared, that does indicate they are courageous. Effective persons do not only emphasize, they systematically remain performing what they have set initially [8].

All those features need intellectual force and stamina; consequently, it is no chance those are some of the features of uncommonly effective persons [8].

As a result, if you have not achieved highest grades in school that is not bad at all. The past does not affect you. The past is only educating. Consider what you have not well realized, in terms of errors you did, simply just in matter of how you will be certain that next future, you perceive what to perform to be assured that results will be as you wish [8] and under no circumstances fail to remember that school is in fact not ever terminated. Effective persons are lasting students [8]. As Corley [8] also wrote: It is now clear that one's IQ can change over their lifetime. It's not fixed. Just because you were a $C$ student at age 17 with an IQ of 100 doesn't necessarily mean you will stay that way. You can increase your IQ all during your life, even into your 80s. Self-made millionaires do certain things every day that improve their brains and continuously increase their intelligence during their lifetimes.

\subsection{Students' Manners to Generate Thoughts}

Smart students employ the next methods to form thoughts concerning anything, whether they are learning math exercises, redesigning a building, or composing a book [1617].

\subsubsection{Perform a Brainstorm}

Brainstorming is a method for generating ideas, determining solutions, and revealing fresh thoughts. As an illustration, if one gives out of cash before pay day every month, manners may be brainstormed to render his money perpetuate lengthy. One may brainstorm fashions to pay for his learning or to locate a work [16].

The main goal of brainstorming is to create several solutions as much as possible. Now and then the craziest, most outlandish thoughts, while impracticable in themselves, may conduct to novel manners to find the key to issues. Table 1 lists the main stages to experiment the brainstorming procedure [16].

Table 1. Principal stages to test the brainstorming operation [16].

\begin{tabular}{|c|c|}
\hline Stage & Description \\
\hline $\begin{array}{l}\text { Stage \#1 } \\
\text { Focus on a single problem or } \\
\text { issue }\end{array}$ & $\begin{array}{l}\text { Express your concentration as an interrogation. Open-ended interrogations that begin with the terms what, how, who, } \\
\text { where, and when usually render efficient focalizing interrogations. }\end{array}$ \\
\hline Stage \#2 & Creativity is improved by a condition of restful attention. If one is taut or worried, peacefulness methods may be applied. \\
\hline Relax & As an illustration, close your eyes and observe your breathing. Next, let yourself to take deeper, longer breaths. \\
\hline \multicolumn{2}{|l|}{ Stage \#3 } \\
\hline $\begin{array}{l}\text { Set a quota or goal for the } \\
\text { number of solutions you want } \\
\text { to generate }\end{array}$ & Objectives provide your subconscious mind with something to work toward. \\
\hline Stage \#4 & Employ a time-clock to schedule it to the minute. Digital sports watches with built-in stopwatches function. Try with \\
\hline Set a time limit & different periods of time. Both short and long brainstorms can be useful. \\
\hline & Brainstorming is founded on attitudes of to lerance and calmness. Receive every thought. If it jumps into your mind, write \\
\hline Stage \#5 & it on sheet. Quantity, not quality, is the target. Keep away from making decisions and assessments for the time of the \\
\hline Allow all answers & $\begin{array}{l}\text { brainstorming period. If you have a problem, think of an unusual thought, and type it. One unusual thought may release an } \\
\text { overflow of other, more practicable solutions. }\end{array}$ \\
\hline Brainstorm with others & thoughts of others, and recall keeping away from assessing or sentencing anyone's thoughts through the brainstorm. \\
\hline
\end{tabular}

After your brainstorming meeting, assess the findings. Put away any actually unusual thoughts, but not before you provide them an occasion [16].

\subsubsection{Concentrate and Leave}

Concentrating and leaving (or letting go) are rotating fragments of the identical procedure. Before anything else, concentrate on an issue or interrogation for a brief moment to the resources of your conscious mind. After that, take a rest and totally let go of searching a solution or reply. This provides your subconscious mind period to function. When you rotate concentrating and calming, the conscious and subconscious fragments of your brain function in accord [16].

Spans of creativity may take only seconds. Be kind with yourself when you observe that your focus has expired. That may be a period to leave. This implies not pushing yourself to be inventive. Work on concentrating for brief moments above all; and, after that, take a pause. As a matter of fact, take a little sleep when you are exhausted. Thomas Edison took recurrent little sleeps; then, the light bulb clicked on.

Toft [16] and Ellis [18] discussed more students' manners to generate thoughts such as cultivate creative serendipity, keep idea files, collect and play with data, etc.

\subsection{Additional Student Activities}

Learning writing $[19,20]$ and mathematical skills is highly recommended for smart students to enhance their creativity [21-24]. Person to person communicative speaking and listening skills are also prescribed for inventive students to improve their creativity [25-29]. More activities such as reading, personal and practical works, and unusual 
educational activities (e.g., community services, travelling, and sport) have appreciated effects on creativity.

\section{Spanning the Link from Research to Practice}

Spikol et al. [27] focused on the necessity to inspect various design manners and digital technology instruments to investigate Technology Enhanced Learning in educational applications. They discussed the use of multidiscipline perspectives of education and didactics, computer science, interaction design, to illustrate the complexity for supporting next generation learning.

Rampino and Ingaramo [28] defined the role of the analogy within the creative phase of the design process and clarified in what way thinking by analogies can help design students to become more creative.

\section{Social Media as a Learning Resource}

Lima et al. [29] discussed the growing effect of the common social media technologies in business teaching and learning. Employing an amalgamation of Google Sites, YouTube and Facebook, they have formed an interactive case study platform which permits content to be reinforced with pertinent videos, images and collaborative inputs (comments, links, tags, etc.). The case, which they named Organixis, reported a fictional software start-up company that generated games for mobile phones. The students were allowed two weeks to cross the dozens of pages on the Google Site page. They were invited to participate at a distance on particular forums of debate which were set up employing a Facebook page, and they were motivated to share their insights, additional materials concerning specific questions or problems, links, videos, etc. on that platform. After a full day of workshops to discuss the Organixis case, they interrogated students and professors with a view to better comprehend how they experienced the active learning elements of this pedagogy, its potential and shortcomings.

Lima et al. [29] showed some early proof that even though media-reinforced cooperative studying domains may assist foster creative and critical thinking [30, 31] (Figure 1) in netgeneration business students; there are obstacles to the acceptation of these instruments both from the viewpoint of teachers and students. Teachers are unwilling to modify their conventional pedagogy, which they consider more fruitful and cost-effective; during the time that students considered that some of the space/time obstacles enjoined were rather fictitious and would have tended to work face to face. Regardless of these rejections, most students liked the nonlinear, multi-media feature of the innovative learning domain and wanted more such actions to be advanced hereafter. Similar studies were performed by Galleto et al. [32] and Conley [33].

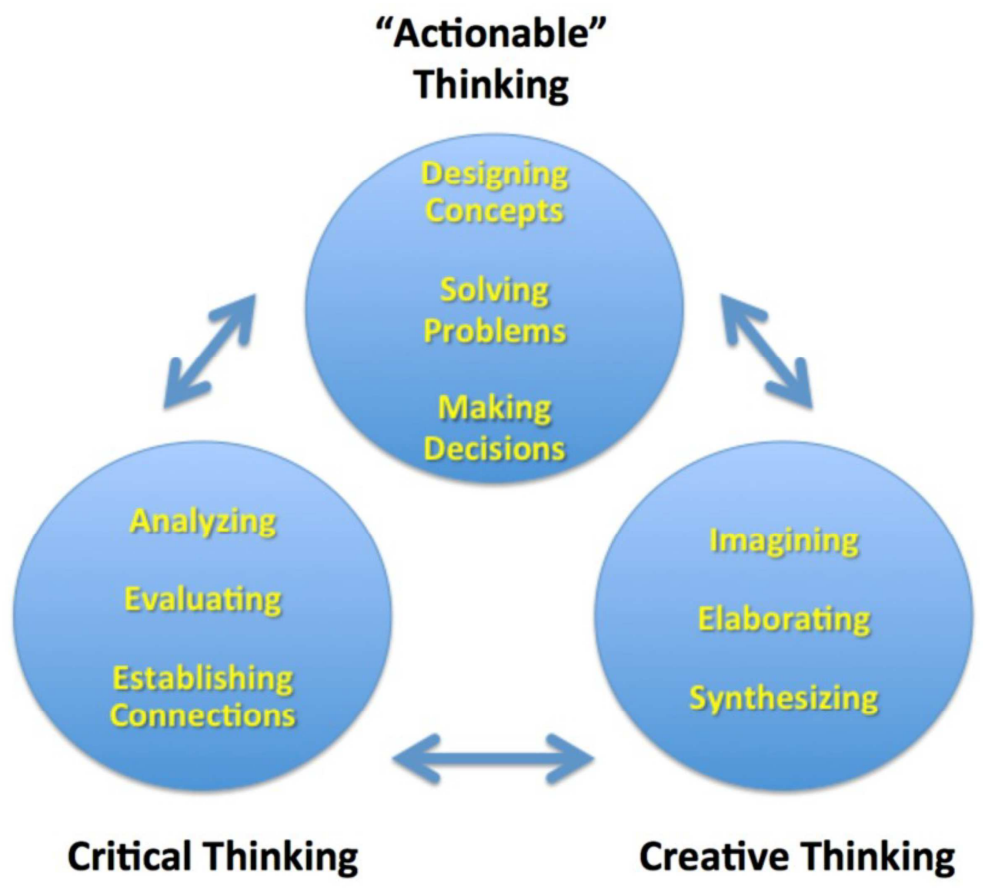

Figure 1. Creative and critical thinking skills [29].

\section{Conclusions}

The main points drawn from this review are listed as below:

1. Nowadays, creativity is crucial in the work world and companies are invited to promote creativity. Managing business findings through directing thoughts upon an innovation operation lets those thoughts to function for both organizations and their clients. With a view to boost the creativity and innovation, that are required to satisfy the needs and defiance of these days, a 
modification in concentration is imposed. Creativity and innovation require the healthy medium in order to develop, one that lets them time, that permits them to concentrate and that gives them inspiration. Those organizations that want to expand creativity, whether they are universities, corporations or governments, should perform their role to generate fields in which single inventors and groups of planners may triumph.

2. Media-reinforced cooperative studying domains may assist foster creative and critical thinking in netgeneration business students; there are obstacles to the acceptation of these instruments both from the viewpoint of teachers and students. Teachers are unwilling to modify their conventional pedagogy, which they consider more fruitful and cost-effective; during the time that students considered that some of the space/time obstacles enjoined were rather fictitious and would have tended to work face to face. Regardless of these rejections, most students liked the non-linear, multi-media feature of the innovative learning domain and wanted more such actions to be advanced hereafter.

\section{References}

[1] Chitra, S. Poddar, Creativity and innovation: A business practice to realize the concept of make in India, Intern. J. Busin. Manage, 2, 702-714, 2015.

[2] Jaruzelski, B., Dehoff K. \& Bordia, R. The Booz Allen Hamilton Global Innovation 1000: Money Isn't Everything. Strategy and Business, 41, 1-14, 2005.

[3] Sternberg, R. J. The Nature of Creativity. Creativity Research Journal, 18 (1), 87-98, 2006.

[4] Al-Sudairi, M. \& Bakry, S. H. Knowledge issues in global innovation index: Assessment of the state of Saudi Arabia versus countries with distinct development. Innovation: Management, Policy \& Practice, 16 (2), 176-183, 2014.

[5] Mayfield, M. \& Mayfield, J. Developing a scale to measure the creative environment perceptions: A questionnaire for investigating garden variety creativity. Creativity Research Journal, 22 (2), 162-169, 2010.

[6] Iqbal, A. Creativity and innovation in Saudi Arabia: An Overview. Management, Policy \& Practice, 13 (3), 376-390, 2011.

[7] Touahmia, M., Ait-Messaoudene, N., Aichouni, N., AlGhamdi, A., Elbadawi, I., Al-Hamali, R. \& Al-Ghonamy, A. Assessment of creativity and innovation at a Saudi University. Intern. J. Adv. Appl. Sci., 4, 48-55, 2017.

[8] J. V. Antonetti, J. R. Garver, 17,000 Classroom visits can't be wrong, Strategies that engage students, promote active learning, and boost achievement, Alexandria, VA, 2015.

[9] J. Haden, 8 of 10 Self-Made millionaires were not 'A' Students. Instead, They Share 1 Trait (19/12/17), https://www.linkedin.com/pulse/8-10-self-made-millionaireswere-students-instead-share-jeff-haden/?trk=emlemail_feed_ecosystem_digest_01-recommended_articles7Unknown\&midToken=AQEWSQjal1SWHw\& fromEmail=fr
omEmail\&ut=1JcZfAuPmd684 1 (accessed on 26/12/17).

[10] J. Haden, The only definition of success that matters, https://www.inc.com/jeff-haden/the-only-definition-ofsuccess-thatmatters.html?lipi=urn\%3Ali\%3 Apage\%3Ad_flagship3_pulse _read\%3BEK0U7mByQa257pB9EM80Ig\%3 0 \% $\% 3$ (accessed on $27 / 12 / 17$ ).

[11] A. Breaux, T. Whitaker, 50 ways to improve student behavior, simple solutions to complex challenges, Taylor \& Francis, New York, 2010.

[12] C. Newport, How to become a straight - A student, Broadway Books, New York, 2007.

[13] T. C. Corley, Most self-made millionaires didn't get A's in school (17/04/15), http://www.businessinsider.com/most-selfmade-millionaires-didnt-get-as-in-school-20154?lipi=urn\%3Ali\%3 Apage\%3Ad_flagship3_pulse_read\%3B5 zjrp423Snas59xeDRvvfA\%3D\%3D (accessed on 27/12/17).

[14] J. Haden, 7 habits of people with remarkable mental toughness (23/07/14), https://www.inc.com/jeff-haden/7-habits-ofpeople-with-remarkable-mentaltoughness.html?lipi=urn\%3Ali\%3Apage\%3Ad_flagship3_pul se read\%3B5zjrp423Snas59xeDRvvfA\%3D\%3 on $27 / 12 / 17$ ).

[15] J. Haden, These 2 four-letter words are the true secret of success (03/05/17), https://www.inc.com/jeff-haden/these-2four-letter-words-are-the-true-secret-ofsuccess.html?lipi=urn\%3Ali\%3 Apage \%3 Ad flagship3 pulse read\%3B5zjrp423Snas59xeDRvvfA $\% 3 \mathrm{D} \% 3 \mathrm{D}$ (accessed on 27/12/17).

[16] D. Toft, The essential guide to becoming a master student, 2nd Ed., Wadsworth, Cengage Learning, Boston, 2012.

[17] M. Schmoker, Focus, Elevating the essentials to radically improve student learning, John Wiley \& Sons, Inc., San Francisco, 2011.

[18] D. J. Saffioti, An instructors view on student success, be an active learner, Clermont, FL, 2008.

[19] D. Ellis, Becoming a master student, 14th Ed., Wadsworth, Cengage Learning, Boston, 2013.

[20] A. Hanson, Brain-friendly strategies for developing student writing skills 2nd Ed., Corwin Press, Thousand Oaks, California, 2009.

[21] D. Ridley, The literature review, A step-by-step guide for students, 2nd Ed., SAGE Publications Ltd, London, 2012.

[22] A. S. Posamentier, Math wonders to inspire teachers and students, Association for Supervision and Curriculum Development (ASCD), Alexandria, VA, 2003.

[23] R. Dixon, V. Frost, R. Haese, M. Haese, S. Haese, Mathematics for the international student, Haese\& Harris Publications, SA 5950, Australia, 2005.

[24] J. Willis, Learning to love math, Teaching strategies that change student attitudes and get results, ASCD, Alexandria, VA, 2010.

[25] D. T. Willingham, Why don't students like school?, John Wiley \& Sons, Inc., San Francisco, 2009. 
[26] J. C. Richards, Person to person communicative speaking and listening skills, 3rd Ed., Oxford University Press, New York, 2006.

[27] D. Spikol, P. Bergström, J. Eliasson, J. Nouri, A. D. Olofsson, J. O. Lindberg, Bridging the distance from research to practice: Designing for technology enhanced learning, NGL 2012: Next Generation Learning Conference: Conference proceedings, 2012, p. 1-9.

[28] L. Rampino, M. O. Ingaramo, Enhancing creativity in higher design education: Analogy as a tool for brainstorming, creativity or conformity?, Building Cultures of Creativity in Higher Education, A conference organized by the University of Wales Institute, Cardiff in collaboration with the Higher Education Academy, Cardiff January 8-10, 2007.

[29] M. Lima, N. Jouini, L. Namaci, T. Fabiani, Social media as a learning resource for business students of the 'net generation':
Using active learning principles to empower creative and critical thinking, Intern. J. Qual. Higher Educ. Instit. 1 (2014) 24-40.

[30] G. Bassham, W. Irwin, H. Nardone, J. M. Wallace, Critical thinking a student's introduction, 4th Ed., McGraw-Hill, New York, 2011.

[31] C. C. Kanar, The confident student, 7th Ed., Wadsworth, Cengage Learning, Boston, 2011.

[32] F. A. Galleto Jr., A. R. J. Barrato, J. M. Bermudez, H. M. D. Buenavista, R. N. Coronel, L. J. Cabuday, G. J. Jeruela, J. R. D. Legurpa, R. T. Magsayo, S. T. Mejos, The effectiveness of MOODLE as a LAN-based instructional teaching learning material, Intern. J. Adv. Appl. Sci. 5 (2018) 97-102.

[33] D. T. Conley, College and career ready, Helping all students succeed beyond high school, John Wiley \& Sons, Inc., San Francisco, 2010. 